\title{
ON THE RADIUS OF UNIVALENCE OF CONVEX COMBINATIONS OF ANALYTIC FUNCTIONS
}

\section{KHALIDA I. NOOR, FATIMA M. ALOBOUDI and NAEELA ALDIHAN}

\author{
Mathematics Department \\ Science College of Education for Girls \\ Malaz, Sitteen Road \\ Riyadh, SAUDI ARABIA
}

(Received July 10, 1982 and in revised form February 21, 1983)

\begin{abstract}
We consider for $\alpha>0$, the convex combinations $f(z)=(1-\alpha) F(z)+\alpha z F^{\prime}(z)$, where $\mathrm{F}$ belongs to different subclasses of univalent functions and find the radius for which is in the same class.
\end{abstract}

KEY WORDS AND PHRASES. Univalent functions, alpha-quasi-convex, starlike, close-toconvex functions, convex combinations.

1980 MATHEMATICS SUBJECT CLASSIFICATION CODES. Primary 30A32, Secondary $30 A 34$.

1. INTRODUCTION.

Let $\mathrm{S}, \mathrm{K}, \mathrm{S} *$ and $\mathrm{C}$ denote the classes of analytic functions in the unit disc

$E=\{z:|z|<1\}$ which are respectively univalent, close-to-convex, starlike, and convex. In $[1,2]$, a new subclass $C^{*}$ of univalent functions was introduced and studied. A function $\mathrm{f}$, analytic in $\mathrm{E}$, belongs to $\mathrm{C}$ * if and only if there exists a convex function $g$ such that for $z \in E$,

$$
\operatorname{Re} \frac{\left(z f^{\prime}(z)\right)^{\prime}}{g^{\prime}(z)}>0
$$

The functions in $C^{*}$ are called quasi-convex and $C \subset C^{*} \subset K \subset S$. It is shown [2] that f $\varepsilon C^{*}$ if and only if $\mathrm{zf}^{\prime} \varepsilon \mathrm{K}$. Recently the functions called $\alpha$-quasi-convex have been defined and their properties studied in [3]. A function $f$, analytic in E, is said to be $\alpha$-quasi-convex if and only if there exists a convex function $g$ such that, for $\alpha$ real and positive

$$
\operatorname{Re}\left\{(1-\alpha) \frac{f^{\prime}(z)}{g^{\prime}(z)}+\alpha \frac{\left(z f^{\prime}(z)\right)^{\prime}}{g^{\prime}(z)}\right\}>0 .
$$


It has been shown [3] that $F$ is $\alpha$-quasi-convex if and only if $f$ with $f(z)=(1-\alpha) F(z)+\alpha z F^{\prime}(z)$ is close-to-convex.

All $\alpha$-quasi-convex functions are close-to-convex.

\section{MAIN RESULTS.}

We shall now study the mapping properties of $f: f(z)=(1-\alpha) F(z)+\alpha z F^{\prime}(z)$, $\alpha>0$, when $F$ belongs to different subclasses of univalent functions.

THEOREM 2.1. Let $F \in S *$ and $\alpha>0$. The function

$$
F(z)=(1-\alpha) F(z)+\alpha z F^{\prime}(z)
$$

is starlike in $|z|<r_{0}$, where

$$
r_{0}=\frac{1}{2 \alpha+\sqrt{4 \alpha^{2}+1-2 \alpha}} \text {. }
$$

This result is sharp.

PROOF. We can write $(2.1)$ as

$$
f(z)=\alpha z^{2-\frac{1}{\alpha}}\left(z^{\frac{1}{\alpha}-1} F(z)\right)^{\prime},
$$

and from this it follows that

$$
F(z)=\frac{1}{\alpha} z^{1-\frac{1}{\alpha}} \int_{0}^{z} z^{\frac{1}{\alpha}-2} f(z) d z
$$

Then

$$
\begin{aligned}
\frac{z F^{\prime}(z)}{F(z)} & =\left\{\left(\left(1-\frac{1}{\alpha}\right) z^{1-\frac{1}{\alpha}} \int_{0}^{z} z^{\frac{1}{\alpha}-2} f(z) d z+f(z)\right) /\left(z^{1-\frac{1}{\alpha}} \int_{0}^{z} z^{\frac{1}{\alpha}-2} f(z) d z\right)\right\} \\
& =\left\{\left(1-\frac{1}{\alpha}\right) \int_{0}^{z} z^{\frac{1}{\alpha}-2} f(z) d z+z^{\frac{1}{\alpha}-1} f(z)\right\} /\left\{\int_{0}^{z} z^{\frac{1}{\alpha}-2} f(z) d z\right\}=h(z),
\end{aligned}
$$

where $\operatorname{Re} h(z)>0$, since $F \varepsilon S *$.

From (2.4), we have

$$
z^{\frac{1}{\alpha}-1} f(z)-\left(\frac{1}{\alpha}-1\right) \int_{0}^{z} z^{\frac{1}{\alpha}-2} f(z) d z=h(z) \int_{0}^{z} z^{\frac{1}{\alpha}-2} f(z) d z .
$$

Differentiating both sides of (2.5), we obtain $\left(\frac{1}{\alpha}-1\right) z^{\frac{1}{\alpha}-2} f(z)+z^{\frac{1}{\alpha}-1} f^{\prime}(z)-\left(\frac{1}{\alpha}-1\right) z^{\frac{1}{\alpha}-2} f(z)=h^{\prime}(z) \int_{0}^{z \frac{1}{\alpha}-2} f(z) d z+h(z) z^{\frac{1}{\alpha}-2} f(z)$. Thus

$$
\frac{z f^{\prime}(z)}{f(z)}=h(z)+\left\{h^{\prime}(z) \int_{0}^{z} z^{\frac{1}{\alpha}-2} f(z) d z\right\} /\left\{z^{\frac{1}{\alpha}-2} f(z)\right\}
$$


Now, using the well-known result [4], $\left|h^{\prime}(z)\right| \leq\{2 \operatorname{Re} h(z)\} /\left(1-r^{2}\right),|z|=r$, we have

$$
\operatorname{Re} \frac{z f^{\prime}(z)}{f(z)} \geq \operatorname{Re} h(z)\left\{1-\frac{2}{1-r^{2}}\left|\frac{\int_{0}^{z} z^{\frac{1}{\alpha}-2} f(z) d z}{z^{\frac{1}{\alpha}-2} f(z)}\right|\right\} .
$$

From (2.1) and (2.3), we have

$$
\begin{aligned}
\frac{z^{\frac{1}{\alpha}-1} f(z)}{\int_{0}^{z} z^{\frac{1}{\alpha}-2} f(z) d z}=\frac{\alpha z\left(z^{\frac{1}{\alpha}-1} F(z)\right)^{\prime}}{\alpha\left(z^{\frac{1}{\alpha}-1} F(z)\right)} & =\frac{\left.z^{\frac{1}{\alpha}-1} z^{\prime} F^{\prime}(z)+\left(\frac{1}{\alpha}-1\right) z^{\frac{1}{\alpha}-2} F(z)\right\}}{\left(z^{\frac{1}{\alpha}-1} F(z)\right)} \\
& =\frac{z F^{\prime}(z)}{F(z)}+\left(\frac{1}{\alpha}-1\right)=h(z)+\left(\frac{1}{\alpha}-1\right),
\end{aligned}
$$

from which it follows that

$$
\left|\left\{z^{\frac{1}{\alpha}-1} f(z) / \int_{0}^{z} z^{\frac{1}{\alpha}-2} f(z) d z\right\}\right| \geq \operatorname{Re}\left\{h(z)+\left(\frac{1}{\alpha}-1\right)\right\} \geq\left(\frac{1}{\alpha}-1\right)+\frac{1-r}{1+r} .
$$

Using (2.7), we have from (2.6)

$$
\begin{aligned}
\operatorname{Re} \frac{z f^{\prime}(z)}{f(z)} & \geq \operatorname{Reh}(z)\left\{1-\left(\frac{2}{1-r^{2}}\right)\left(\frac{r+r^{2}}{\frac{1}{\alpha}+\left(\frac{1}{\alpha}-2\right) r}\right)\right\} \\
& =\operatorname{Reh}(z)\left\{\left(\frac{1}{\alpha}-4 r-\left(\frac{1}{\alpha}-2\right) r^{2}\right)\right\} /\left\{(1-r)\left(\frac{1}{\alpha}+\left(\frac{1}{\alpha}-2 r\right)\right\} .\right.
\end{aligned}
$$

The right hand side of (2.8) is positive for $r<r_{0}$, where $r_{o}$ is given by (2.2). This result is sharp as can be seen by

$$
\begin{aligned}
f_{0}(z) & =\left\{\alpha\left(z\left(\frac{1}{\alpha}-\left(\frac{1}{\alpha}-2\right) z\right)\right)\right\} /(1-z)^{3} \\
& =(1-\alpha) F_{0}(z)+\alpha z F_{0}^{\prime}(z),
\end{aligned}
$$

where

$$
F_{0}(z)=\frac{z}{(1-z)^{2}} \varepsilon S^{*} .
$$

REMARK 2.1. Let $\mathrm{f} \in \mathrm{C}$, then $\mathrm{f}$, given by (2.1), is convex for $|z|<r_{0}$, where $r_{0}$ is given by (2.2). The proof follows on the same lines as in Theorem 2.1. See also [5] and [6].

REMARK 2.2. In [6], Nikolaeva and Repnina treated the same problem, with a different notation, for the convex and starlike functions of order $\beta$. Theorem 2.1 follows from their result when we take $\dot{\beta}=0$ for $0 \leq \alpha \leq 1$. On the other hand, our proof of Theorem 2.1 is much simpler and the result holds for all $\alpha>0$. 
THEOREM 2.2. Let $F \varepsilon K$ and $f(z)=(1-\alpha) F(z)+\alpha z F^{\prime}(z), \alpha>0$. Then $f$ is close-to-convex in $|z|<r_{0}, r_{0}$ is given by (2.2). The function $f_{0}$ in (2.9) shows that this result is sharp.

PROOF. Since $F \varepsilon K$, there exists a $G \varepsilon S *$ such that, for $z \varepsilon E, \operatorname{Re} \frac{z F^{\prime}(z)}{G(z)}>0$. Now let $g(z)=(1-\alpha) G(z)+\alpha z G^{\prime}(z)$. Then by Theorem $2.1, g$ is starlike for $|z|<r_{0}$, $r_{0}$ is defined by $(2.2)$. Using the same technique of Theorem 2.1 , we can easily show that $\operatorname{Re} \frac{z f^{\prime}(z)}{g(z)}>0$ for $|z|<r_{0}$.

REMARK 2.3. For $\alpha=\frac{1}{2}$, this result has been proved in [7].

As an easy consequence of (1.3) and Theorem 2.2, we have the following.

COROLLARY 2.1. Let $F \in K$ and $f(z)=(1-\alpha) F(z)+\alpha z F^{\prime}(z), \alpha>0$. Then $F$ is $\alpha-$ quasi-convex in $|z|<r_{0}$. This means that the radius of $\alpha$-quasi-convexity for closeto-convex functions is given by $(2.2)$.

THEOREM 2.3. Let $F \in C^{*}$ and $\alpha>0$. Let $f(z)=(1-\alpha) F(z)+\alpha z F^{\prime}(z)$. Then $f$ is in $C^{\star}$, for $|z|<r_{0}, r_{0}$ is given by $(2.2)$.

PROOF. Since $F \in C^{*}$, there exists a $G \in C$ such that for $z \varepsilon E, \operatorname{Re} \frac{\left(z F^{\prime}(z)\right)^{\prime}}{G^{\prime}(z)}>0$. Now let $g(z)=(1-\alpha) G(z)+\alpha z G^{\prime}(z)$, then $g$ is convex in $|z|<r_{0}$. We can write

$$
\left.f(z)=(1-\alpha) F(z)+\alpha z F^{\prime}(z)=z^{2-\frac{1}{\alpha}}{ }_{\left(z^{\frac{1}{\alpha}}-1\right.} F(z)\right)^{\prime}
$$

and

$$
g(z)=(1-\alpha) G(z)+\alpha z G^{\prime}(z)=z^{2-\frac{1}{\alpha}}\left(z^{\frac{1}{\alpha}-1} G(z)\right)^{\prime} .
$$

Thus

$$
\left.\frac{\left(z f^{\prime}(z)\right)^{\prime}}{g^{\prime}(z)}=\left(\left(z^{2-\frac{1}{\alpha}}\left(z^{\frac{1}{\alpha}-1} F(z)\right)^{\prime}\right)^{\prime}\right)^{\prime}\right) /\left(z^{2-\frac{1}{\alpha}}\left(\left(z^{\frac{1}{\alpha}-1} G(z)\right)^{\prime}\right)^{\prime}\right)
$$

Now

$$
\begin{aligned}
& \left(z\left(z^{2-\frac{1}{\alpha}}\left(z^{\frac{1}{\alpha}-1} F(z)\right)^{\prime}\right)^{\prime}\right)^{\prime}=\left(z\left(\left(\frac{1}{\alpha}-1\right) F(z)+z F^{\prime}(z)\right)^{\prime}\right)^{\prime}=\left(\frac{1}{\alpha} z F^{\prime}(z)+z^{2} F^{\prime \prime}(z)\right)^{\prime} \\
& =\left(z^{2-\frac{1}{\alpha}}\left(\frac{1}{\alpha} z^{\frac{1}{\alpha}-1} F^{\prime}(z)+z^{\frac{1}{\alpha}} F^{\prime \prime}(z)\right)\right)^{\prime}=\left(z^{2-\frac{1}{\alpha}}\left(z^{\frac{1}{\alpha}-1} z F^{\prime}(z)\right)^{\prime}\right) !
\end{aligned}
$$

Let $z F^{\prime}(z)=H(z)$, then from $(2.10)$, we have

$$
\left.\frac{\left(z f^{\prime}(z)\right)^{\prime}}{g^{\prime}(z)}=\left(z^{2-\frac{1}{\alpha}}{ }_{\left(z^{\frac{1}{\alpha}}-1\right.} H(z)\right)^{\prime}\right)^{\prime} /\left(z^{2-\frac{1}{\alpha}}\left(z^{\frac{1}{\alpha}-1} G(z)\right)^{\prime}\right)^{\prime}
$$

Since from Theorem 2.2, the function $(1-\alpha) H(z)+z H^{\prime}(z)=z^{2-\frac{1}{\alpha}}\left(z^{\frac{1}{\alpha}-1} H(z)\right)^{\prime}$ belongs to $K$ with respect to a convex function $g: g(z)=(1-\alpha) G(z)+\alpha z G^{\prime}(z)$ in 
$|z|<r_{0}$, so $f$ is in $C^{*}$ for $|z|<r_{0}$, where $r_{0}$ is given by (2.2).

REMARK 2.4. For $F \in C^{*}$ and $\alpha=\frac{1}{2}$, Theorem 2.3 has been proved in [1].

We now deal with a generalized form of (1.1) by taking $g$ to be starlike and prove the following.

THEOREM 2.4. Let $F$ be analytic in $E$ and let for $z \in E, \operatorname{Re} \frac{\left(z F^{\prime}(z)\right)^{\prime}}{G^{\prime}(z)}>0, G \varepsilon S^{*}$. Let $f(z)=(1-\alpha) F(z)+\alpha z F^{\prime}(z)$ and $g(z)=(1-\alpha) G(z)+\alpha z G^{\prime}(z)$, with $\alpha>0$. Then $\operatorname{Re} \frac{\left(z f^{\prime}(z)\right)^{\prime}}{g^{\prime}(z)}>0$ for $|<|<r_{1}$, where

$$
r_{1}=\frac{1}{3 \alpha+\sqrt{9 \alpha^{2}+1-2 \alpha}}
$$

For $\alpha=\frac{1}{2}$, the problem has been solved in [8].

PROOF. From (2.3), we can write

$$
\begin{aligned}
F(z) & =\frac{1}{\alpha} z^{1-\frac{1}{\alpha}} \int_{0}^{z} z^{\frac{1}{\alpha}-2} f(z) d z \\
z F^{\prime}(z) & =\frac{1}{\alpha} z^{1-\frac{1}{\alpha}}\left(\left(1-\frac{1}{\alpha}\right) \int_{0}^{z} z^{\frac{1}{\alpha}-2} f(z) d z+z^{\frac{1}{\alpha}-1} f(z)\right) \\
& =\frac{1}{\alpha} z^{1-\frac{1}{\alpha}}\left(\int_{0}^{z} z^{\frac{1}{\alpha}-1} f^{\prime}(z) d z\right) .
\end{aligned}
$$

Thus

$$
\frac{\left(z F^{\prime}(z)\right)^{\prime}}{G^{\prime}(z)}=\frac{\left(z^{\frac{1}{\alpha}} f^{\prime}(z)-\left(\frac{1}{\alpha}-1\right) \int_{0}^{z} z^{\frac{1}{\alpha}-1} f^{\prime}(z) d z\right)}{\int_{0}^{z} z^{\frac{1}{\alpha}-1} g^{\prime}(z) d z}=h(z),
$$

where $\operatorname{Re} h(z)>0, z \in E$.

From (2.11), we write

$$
z^{\frac{1}{\alpha}} f^{\prime}(z)-\left(\frac{1}{\alpha}-1\right) \int_{0}^{z} z^{\frac{1}{\alpha}-1} f^{\prime}(z) d z=h(z) \int_{0}^{z} z^{\frac{1}{\alpha}-1} g^{\prime}(z) d z .
$$

Differentiating both sides, and simplifying, we obtain

$$
\frac{\left(z f^{\prime}(z)\right)^{\prime}}{g^{\prime}(z)}=h(z)+\frac{h^{\prime}(z)\left(\int_{0}^{z} z^{\frac{1}{\alpha}-1} g^{\prime}(z) d z\right)}{z^{\frac{1}{\alpha}-1} g^{\prime}(z)} .
$$

Using $\left|h^{\prime}(z)\right| \leq \frac{2 \operatorname{Re} h(z)}{1-r^{2}},(2.12)$ gives 


$$
\operatorname{Re} \frac{\left(z f^{\prime}(z)\right)^{\prime}}{g^{\prime}(z)} \geq \operatorname{Re} h(z)\left[1-\frac{2}{1-r^{2}}\left|\left(\int_{0}^{z} z^{\frac{1}{\alpha}-1} g^{\prime}(z) d z\right) /\left(z^{\frac{1}{\alpha}-1} g^{\prime}(z) d z\right)\right|\right]
$$

Now

$$
\left(z^{\frac{1}{\alpha}} g^{\prime}(z)\right) /\left(\int_{0}^{z} z^{\frac{1}{\alpha}-1} g^{\prime}(z) d z\right)=\frac{(1 / \alpha) G^{\prime}(z)+z G^{\prime \prime}(z)}{G^{\prime}(z)}=\left(\frac{1}{\alpha}-1\right)+\frac{\left(z G^{\prime}(z)\right)^{\prime}}{G^{\prime}(z)} .
$$

Since $G \in S *$, so

$$
\left|\frac{\left(z G^{\prime}(z)\right)^{\prime}}{G^{\prime}(z)}\right| \geq \frac{1-4 r+r^{2}}{1-r^{2}} .
$$

From (2.13), (2.14) and (2.15), we obtain

$$
\begin{aligned}
\operatorname{Re} \frac{\left(z f^{\prime}(z)\right)^{\prime}}{g^{\prime}(z)} & \geq \operatorname{Re} h(z)\left[1-\frac{2}{1-r^{2}} \frac{r\left(1-r^{2}\right)}{\frac{1}{\alpha}-4 r-\left(\frac{1}{\alpha}-2\right) r^{2}}\right] \\
& =\operatorname{Re} h(z) \frac{1-6 \alpha r-(1-2 \alpha) r^{2}}{1-4 \alpha r-(1-2 \alpha) r^{2}},
\end{aligned}
$$

and this positive for $|z|<r_{1}$, where

$$
\mathrm{r}_{1}=\frac{1}{3 \alpha+\sqrt{9 \alpha^{2}+1-2 \alpha}} \text {. }
$$

ACKNOWLEDGEMENT. The authors are grateful for the referee's helpful comments and suggestions on the earlier version of this paper. In particular, the reference to Nikolaeva and Repnina was kindly supplied by him.

\section{REFERENCES}

1. NOOR, K. INAYAT. On a subclass of close-to-convex functions, Comm. Math. Univ. St. Pauli 29 (1980), 25-28.

2. NOOR, K. INAYAT and THOMAS, D.K. On quasi-convex univalent functions, Inter. J. Math. and Math. Sci. $\underline{3}$ (1980), 255-266.

3. NOOR, K. INAYAT and ALOBOUDI, F.M. Alpha-quasi-convex functions, to appear.

4. LIBERA, R.J. Some radius of convexity problems, Duke Math. J. 31 (1964), 143-158.

5. CAMPBELL, D.M. A survey of problems of the convex combination of univalent functions, Rockey Mount J. Math. $\underline{5}$ (1975), 475-492.

6. NIKOLAEVA, R.V. and REPNINA, L.G. A certain generalization of theorems due to Livingston, (Russian), Ukrain Mat. Z. 24 (1972), 268-273, MR45 \# 5336.

7. LIVINGSTON, A.E. On the radius of univalence of certain analytic functions, Proc. Amer. Math. Soc. 17 (1966), 352-357.

8. NOOR, K INAYAT and ALDIHAN, N. A subclass of close-to-convex functions, to appear. 


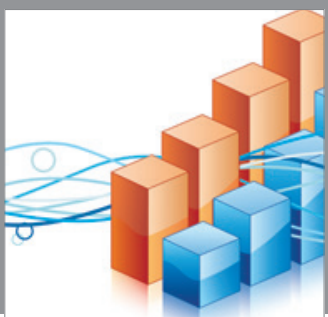

Advances in

Operations Research

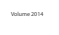

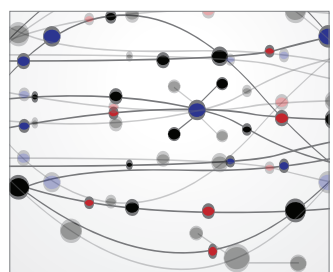

\section{The Scientific} World Journal
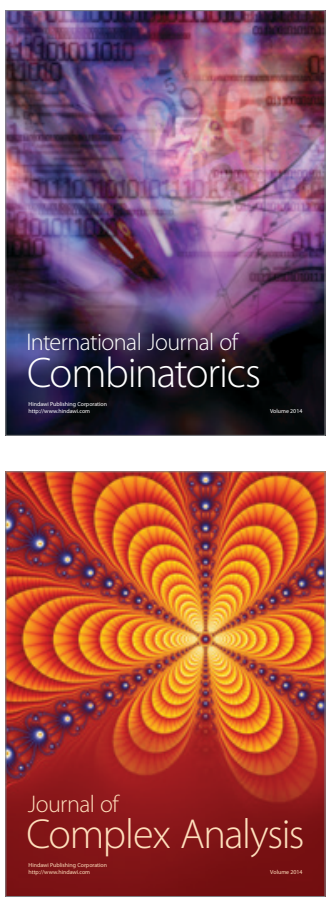

International Journal of

Mathematics and

Mathematical

Sciences
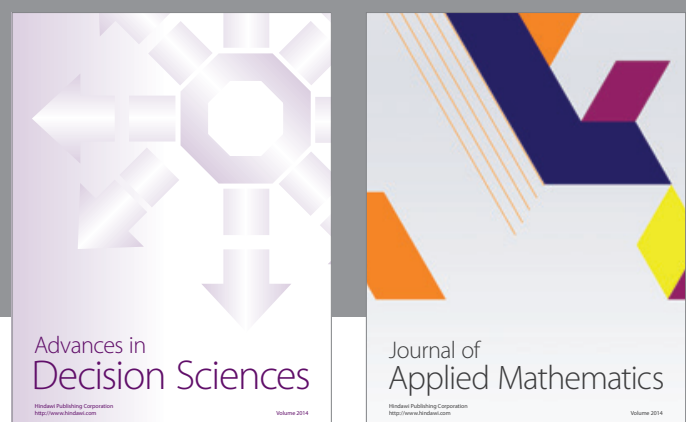

Journal of

Applied Mathematics
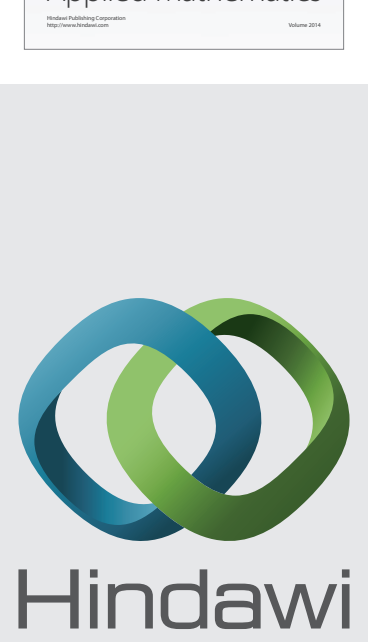

Submit your manuscripts at http://www.hindawi.com
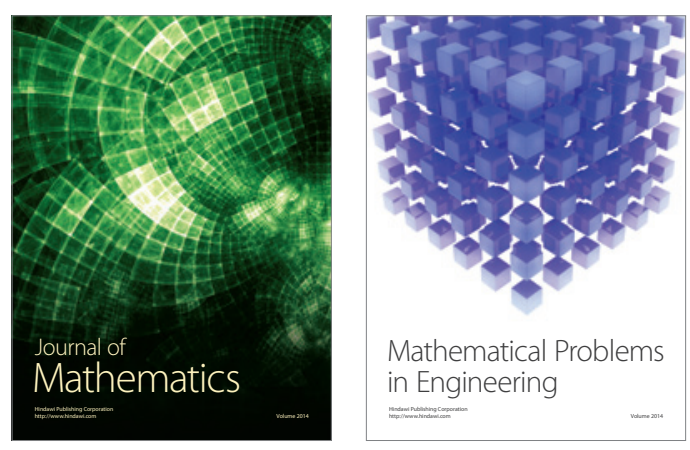

Mathematical Problems in Engineering
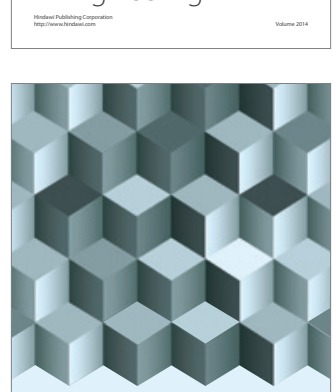

Journal of

Function Spaces
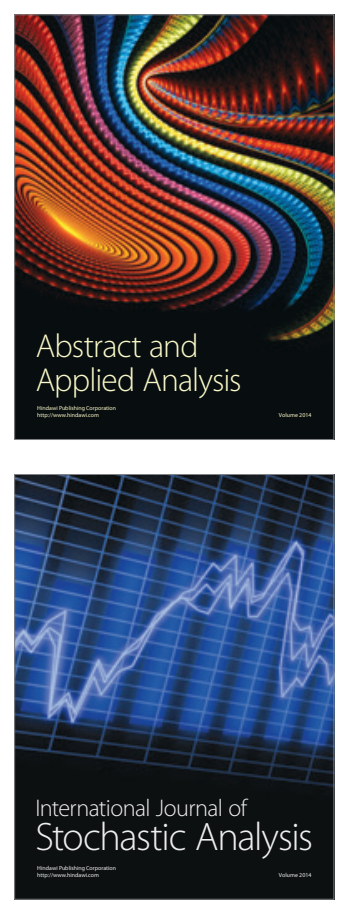

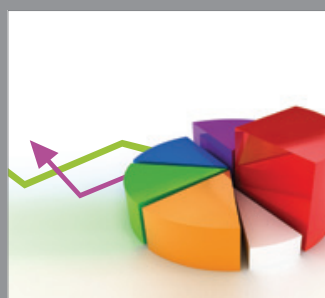

ournal of

Probability and Statistics

Promensencen
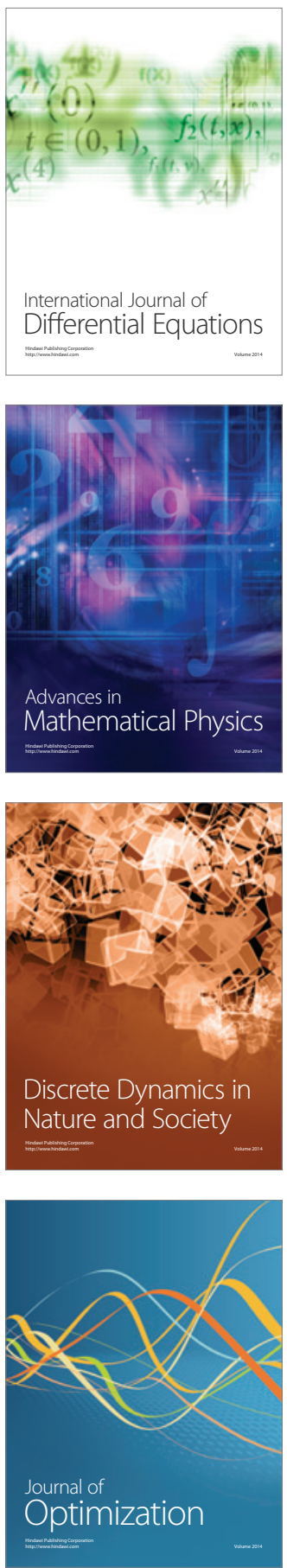